\title{
Metformin-mediated growth inhibition involves suppression of the IGF-I receptor signalling pathway in human pancreatic cancer cells
}

\author{
Emelie Karnevi, Katarzyna Said, Roland Andersson ${ }^{*}$ and Ann H Rosendahl
}

\begin{abstract}
Background: Epidemiological studies have shown direct associations between type 2 diabetes and obesity, both conditions associated with hyperglycaemia and hyperinsulinemia, and the risk of pancreatic cancer. Up to $80 \%$ of pancreatic cancer patients present with either new-onset type 2 diabetes or impaired glucose tolerance at the time of diagnosis. Recent population studies indicate that the incidence of pancreatic cancer is reduced among diabetics taking metformin. In this study, the effects of exposure of pancreatic cancer cells to high glucose levels on their growth and response to metformin were investigated.
\end{abstract}

Methods: The human pancreatic cancer cell lines AsPC-1, BxPC-3, PANC-1 and MIAPaCa-2 were grown in normal $(5 \mathrm{mM})$ or high $(25 \mathrm{mM})$ glucose conditions, with or without metformin. The influence by metformin on proliferation, apoptosis and the AMPK and IGF-IR signalling pathways were evaluated in vitro.

Results: Metformin significantly reduced the proliferation of pancreatic cancer cells under normal glucose conditions. Hyperglycaemia however, protected against the metformin-induced growth inhibition. The anti-proliferative actions of metformin were associated with an activation of AMP-activated protein kinase AMPK $^{\text {Thr172 }}$ together with an inhibition of the insulin/insulin-like growth factor-I (IGF-I) receptor activation and downstream signalling mediators IRS-1 and phosphorylated Akt. Furthermore, exposure to metformin during normal glucose conditions led to increased apoptosis as measured by poly(ADP-ribose) polymerase (PARP) cleavage. In contrast, exposure to high glucose levels promoted a more robust IGF-I response and Akt activation which correlated to stimulated AMPK $^{\text {Ser485 }}$ phosphorylation and impaired AMPK ${ }^{\text {Thr172 }}$ phosphorylation, resulting in reduced anti-proliferative and apoptotic effects by metformin.

Conclusion: Our results indicate that metformin has direct anti-tumour activities in pancreatic cancer cells involving AMPK ${ }^{T h r 172}$ activation and suppression of the insulin/IGF signalling pathways. However, hyperglycaemic conditions enhance the insulin/IGF-I responses resulting in an altered AMPK activation profile and prevent metformin from fully switching off the growth promoting signals in pancreatic cancer cells.

Keywords: Pancreatic cancer, Type 2 diabetes mellitus, Hyperglycaemia, Metformin, Insulin-like growth factor (IGF), Signalling

\footnotetext{
* Correspondence: roland.andersson@med.lu.se

Department of Surgery, Clinical Sciences Lund, Skåne University Hospital and Lund University, Lund SE-221 84, Sweden
} 


\section{Background}

Over recent decades the incidence of metabolic disorders, such as obesity and type 2 diabetes mellitus, has increased as a consequence of westernized lifestyle and changes in diet. These conditions are in turn associated with an increased risk of developing cancer [1-3]. Epidemiological studies have demonstrated that obesity and type 2 diabetes are among the top three modifiable risk factors for pancreatic cancer [2,4-8]. Almost $80 \%$ of pancreatic cancer patients present with either new-onset type 2 diabetes or impaired glucose tolerance at the time of diagnosis $[9,10]$. The relationship between type 2 diabetes and pancreatic cancer is complex and it remains unclear whether type 2 diabetes contributes to the development of pancreatic cancer or if precancerous cells cause the diabetes. Individuals with elevated fasting glucose and glycated haemoglobin $\left(\mathrm{H}_{\mathrm{b}} \mathrm{A}_{1 \mathrm{c}}\right)$ levels $[11,12]$, or with higher c-peptide or insulin levels have a two to four-fold increase in the risk of pancreatic cancer [1,7]. Type 2 diabetes patients also demonstrate an increased risk of pancreatic cancer-related death as compared with those without diabetes [13]. Type 2 diabetes is characterized by hyperglycaemia and peripheral insulin resistance with compensatory hyperinsulinemia. Aside from its metabolic actions, insulin can mediate direct mitogenic effects through the insulin receptor (IR) and insulin-like growth factor I (IGF-I) receptor (IGF-IR). Insulin may also affect the cancer risk indirectly via increased production and bioavailability of IGF-I $[6,14]$. Additionally, hyperglycaemia can increase the sensitivity to IGF-I [4], thereby enhancing its mitogenic potential and providing an additional link between type 2 diabetes and cancer.

Insulin-sensitizing and glucose lowering drugs, such as metformin, are used as first-line treatment in the management of type 2 diabetes to improve glycaemic control in patients with insulin resistance. The key metabolic action of metformin involves the inhibition of hepatic glucose secretion, which consequently decreases the hyperinsulinemia. This mechanism is mediated via activation of the energy-sensing AMP-activated protein kinase (AMPK) in hepatocytes, through the liver kinase B1 (LKB1) signalling pathway [15]. Although metformin can lower blood glucose, the levels rarely remain within the normal range and as the type 2 diabetes progresses, additional medication such as exogenous insulin is often required to control patients' hyperglycaemia $[16,17]$. In addition to its anti-diabetic effects, metformin has recently been postulated to have a protective role against cancer. Epidemiological and retrospective studies have demonstrated that diabetic patients taking metformin not only have a lower incidence of pancreatic cancer, but also an improved cancer outcome [18-21]. The indicated anti-neoplastic activity of metformin may relate to reduced plasma insulin concentrations or by direct effects on the tumour cells. Recent studies suggest that metformin-induced AMPK activation at $\mathrm{Thr}^{172}$ inhibits the central growth control node mammalian target of rapamycin mTOR, thus preventing protein synthesis and cell proliferation [22]. Metformin has recently been shown to possess anti-tumour effects, both in AMPK-dependent and independent manners [23-25].

Although an increasing number of studies demonstrate the anti-tumour effects of metformin, relatively little is known about the effects and underlying mechanisms of metformin on pancreatic cancer cells. The goal of this study was to examine the direct effects of metformin on human pancreatic cancer cells in the context of normal or elevated glucose levels. Effects on proliferation, apoptosis, AMPK activation and influence on and by the IGF-I pathway were analysed.

\section{Methods}

\section{Materials}

All chemicals and reagents were purchased from Sigma Aldrich (St. Louis, Mo, USA) unless stated otherwise. Cell culture media, penicillin/streptomycin and fetal bovine serum (FBS) were purchased from Invitrogen (Paisley, UK). IGF-I was purchased from GroPep (Adelaide, Australia). MTT; Cell Proliferation Kit I was derived from Roche (Mannheim, Germany). Anti-cleaved PARP, antiphospho-AMPK ${ }^{\text {Thr172, }}$ anti-phospho-AMPK ${ }^{\text {Ser485, anti- }}$ AMPK, anti-IRS-1, anti-phospho-IGF-IR $\beta /$ phospho-IR $\beta$, anti-phospho-Akt ${ }^{\mathrm{Ser} 473}$ and anti-Akt antibodies were purchased from Cell Signaling Technology Inc. (Beverly, MA, USA). Anti-IGF-IR $\beta$ was obtained from Santa Cruz Biotechnology (Santa Cruz, CA, USA) and anti-GAPDH from Millipore (Temecula, CA, USA).

\section{Cell culture}

The human pancreatic adenocarcinoma cell lines AsPC-1, BxPC-3, PANC-1 and MIAPaCa-2 were purchased from ATCC-LGC Standards (Manassas, VA, USA). The cells were maintained in RPMI1640 or DMEM supplemented with $10 \% \mathrm{FBS}$ and antibiotics $(100 \mathrm{U} / \mathrm{ml}$ penicillin and 100 $\mu \mathrm{g} / \mathrm{ml}$ streptomycin) in a humified $5 \% \mathrm{CO}_{2}$ atmosphere at $37^{\circ} \mathrm{C}$. All experiments were performed in glucose-free RPMI1640 or DMEM supplemented with $5 \mathrm{mM}$ (normal) or $25 \mathrm{mM}$ (high) D-glucose, $2 \mathrm{mM}$ L-glutamine and antibiotics as above (serum-free media; SFM), unless stated otherwise.

\section{MTT proliferation assay}

Cells were plated $\left(10 \times 10^{3}\right.$ cells/well $)$ in 96 -well plates in growth media with $5 \mathrm{mM}$ glucose for $24 \mathrm{~h}$ before switching to SFM with $5 \mathrm{mM}$ or $25 \mathrm{mM}$ glucose for another $24 \mathrm{~h}$. Cells were subsequently dosed with increasing concentrations of metformin $(0-20 \mathrm{mM})$ in 
SFM with $5 \mathrm{mM}$ or $25 \mathrm{mM}$ glucose in sextuplicates ( $\mathrm{n}=6$ wells). SFM with either $5 \mathrm{mM}$ or $25 \mathrm{mM}$ was used as control. Following incubation for 24-72 h, cell proliferation was assessed by MTT according to the manufacturer's instructions. The samples were measured on a Labsystems Multiskan Plus plate reader (test wavelength $595 \mathrm{~nm}$, reference wavelength $660 \mathrm{~nm}$ ) using the DeltaSoft JV software (BioMetallics Inc., Princeton, NJ, USA).

\section{Western immunoblotting}

Cells were cultured $\left(6 \times 10^{5}\right.$ cells/well $)$ in 6 -well plates for $24 \mathrm{~h}$. After an additional $24 \mathrm{~h}$ in normal glucose SFM, the cells were dosed with metformin (0-20 mM) in SFM or $1 \%$ FBS SFM with 5 or $25 \mathrm{mM}$ glucose for $24 \mathrm{~h}$. Cells were then spiked with IGF-I (100 ng/ml) as indicated for the final $15 \mathrm{~min}$ of incubation. Cells were lysed as previously described [26]. Protein concentrations were determined using BCA protein assay reagent kit (ThermoFisherScientific, Waltham, MA, USA). Lysates were dissolved in Laemmli buffer, boiled for 5 minutes and separated (60-65 $\mu$ g protein per lane) by SDS-PAGE ( $8 \%$ or $12 \%)$ and transferred to $0.2 \mu \mathrm{m}$ Hybond-C extra nitrocellulose membrane (Amersham Biosciences, Buckinghamshire, UK). The membranes were blocked with $5 \%(\mathrm{w} / \mathrm{v}) \mathrm{milk}$ in Tris-buffered saline Tween-20 (TBST) and probed overnight $\left(4^{\circ} \mathrm{C}\right)$ with the indicated antibodies, all used at dilutions of 1:1000. Immunoblotted proteins were detected using HRP-conjugated secondary antibodies and visualized by SuperSignal West Extended Duration Substrate (ThermoFisherScientific) using BioRad Chemidoc XRS + system and Image lab software.

\section{Statistical analysis}

Proliferation data are expressed as means \pm SE of six replicate wells. Densitometry analyses of Western blot data were performed using Image J software (NIH, USA) and are expressed as means \pm SE of three individual experiments, unless stated otherwise. Statistical analyses were

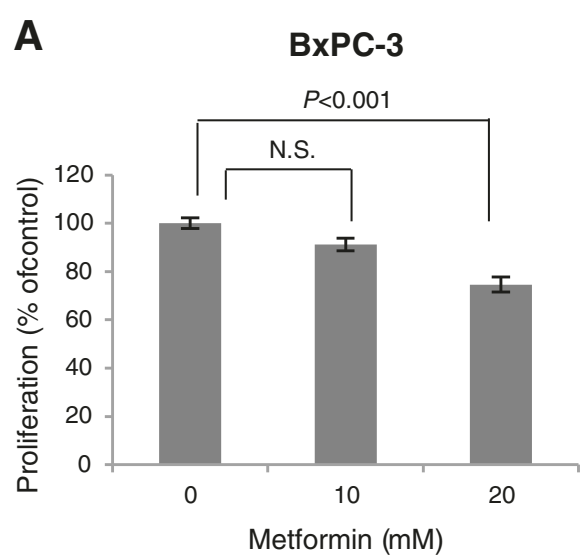

C

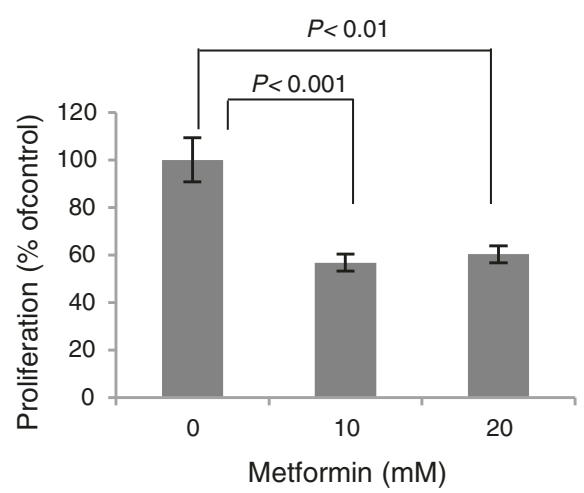

B

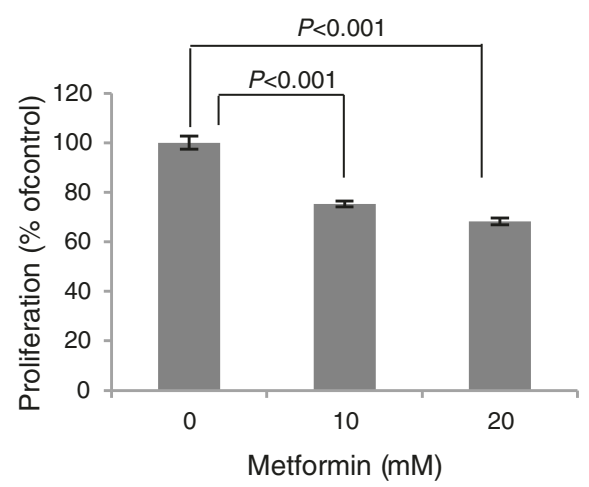

D

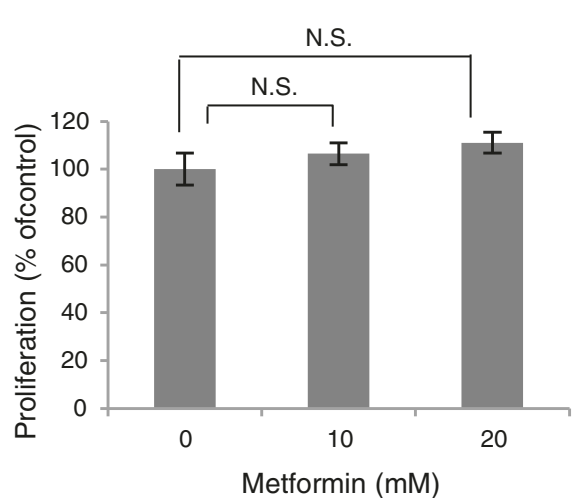

Figure 1 Metformin acts as a growth inhibitor for human pancreatic cancer cells. (A) BxPC-3, (B) MIAPaCa-2, (C) PANC-1 and (D) AsPC-1 pancreatic cancer cells were seeded in 96-well plates in normal (5 mM) glucose-containing growth media with $10 \%$ FBS for $24 \mathrm{~h}$, followed by $24 \mathrm{~h}$ in $5 \mathrm{mM}$ glucose-containing SFM. The cells were then dosed with or without metformin in normal glucose SFM for an additional $24 \mathrm{~h}$. Results are shown as percentage of SFM control and represent mean \pm SE of six replicate wells. P-values are based on one-way ANOVA with Bonferroni post hoc test. N.S., not significant. One representative out of three independent experiments is shown. 
performed by one- or two-way ANOVA with Bonferroni post hoc test using GraphPad prism software. A $P$-value of $<0.05$ was considered statistically significant.

\section{Results}

Metformin acts as a growth inhibitor for human pancreatic cancer cells

To examine the effect of metformin on cell proliferation, a panel of human pancreatic cancer cell lines were exposed to metformin for $24 \mathrm{~h}$ in normal glucose levels $(5 \mathrm{mM})$.
Metformin induced a significant 20-40\% growth inhibition of BxPC-3 $(P<0.001$; Figure $1 \mathrm{~A})$, MIAPaCa-2 $(P<0.001$; Figure $1 \mathrm{~B})$ and PANC-1 $(P<0.01$; Figure $1 \mathrm{C})$, whereas no growth inhibitory effect was observed on AsPC-1 pancreatic cancer cells (Figure 1D).

\section{Hyperglycaemia suppresses metformin-induced growth inhibition}

The influence of increased levels of glucose on the sensitivity to metformin was examined. When BxPC-3 and
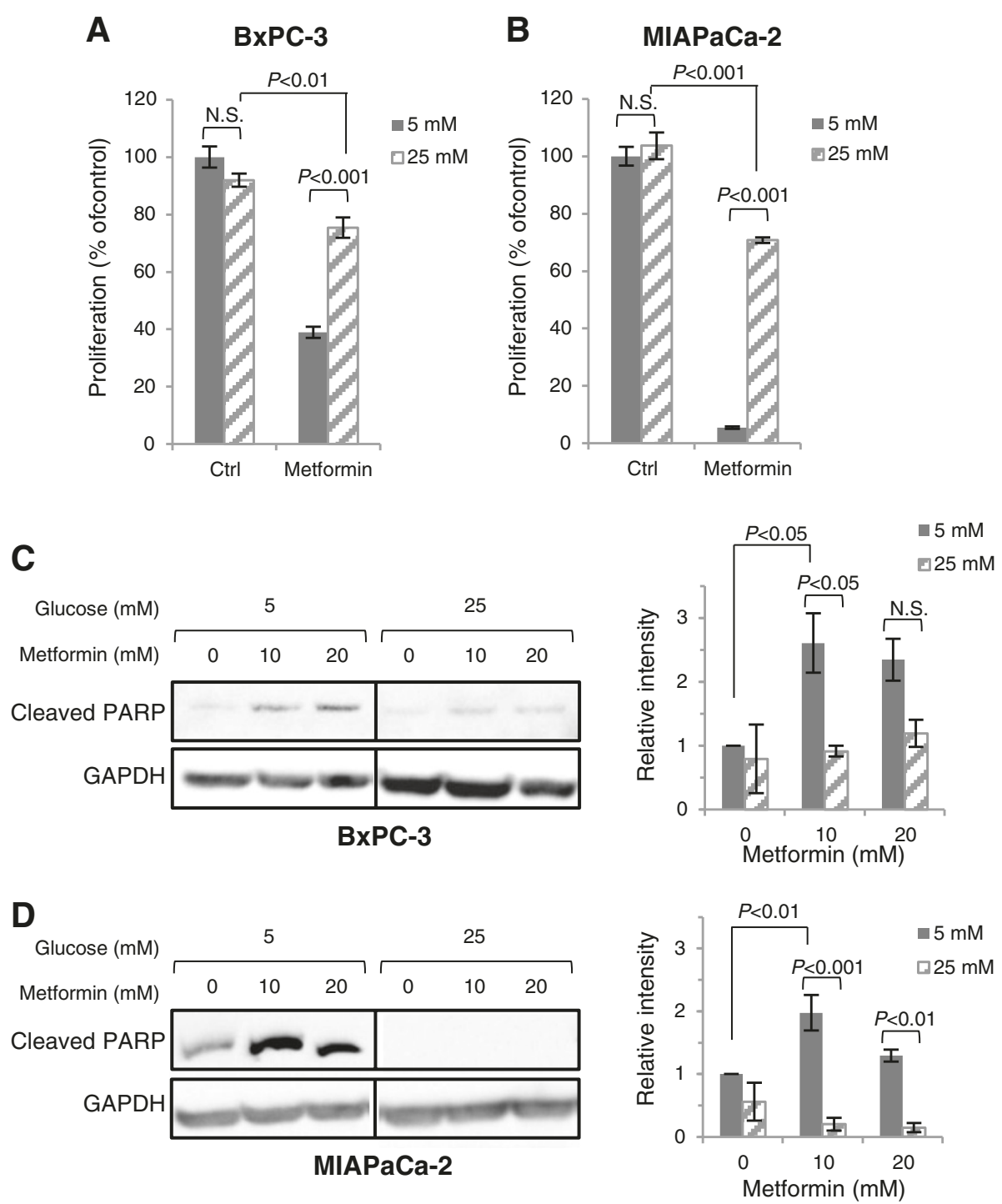

Figure 2 High glucose reduces metformin-induced growth suppression and apoptosis. (A) BxPC-3 and (B) MIAPaCa-2 cells were treated with or without $10 \mathrm{mM}$ metformin in normal $(5 \mathrm{mM})$ or high $(25 \mathrm{mM})$ glucose-containing SFM for $72 \mathrm{~h}$ and proliferation was assessed by MTT assay. Graphs represent changes in proliferation and mean \pm SE of six replicate wells are depicted. $P<0.05$, two-way ANOVA with Bonferroni post hoc test. N.S., not significant. (C) BXPC-3 and (D) MIAPaCa-2 cells were treated in 1\% FBS SFM with either 5 or $25 \mathrm{mM}$ glucose, with or without metformin for $24 \mathrm{~h}$ and processed for levels of cleaved PARP as an indicator of apoptosis by Western immunoblotting. Histograms show densitometry evaluation of relative difference in cleaved PARP intensity and represent means \pm SE of three independent experiments. P-values are based on two-way ANOVA with Bonferroni post hoc test. Blots shown are representative assays from three independent experiments. 
MIAPaCa-2 cells were exposed to metformin for $72 \mathrm{~h}$ under hyperglycaemic conditions $(25 \mathrm{mM})$, the proliferation was decreased by $18 \%$ and $32 \%$, respectively. Hyperglycaemia significantly reduced the efficacy of metformin as compared with normal ( $5 \mathrm{mM})$ glucose levels where a $56 \%$ and $95 \%$ growth inhibition was obtained in BxPC-3 and MIAPaCa- 2 , respectively $(P<0.001$; Figure $2 \mathrm{~A}, \mathrm{~B})$. The growth inhibitory effects by metformin in normal glucose conditions correlated with a significant induction of cleaved PARP, as an indicator of apoptosis $(P<0.05$; Figure $2 \mathrm{C}, \mathrm{D})$. In contrast, levels of cleaved PARP in response to metformin were significantly decreased or absent at high glucose conditions, consistent with the reduced sensitivity of $\mathrm{BxPC}-3$ and MIAPaCa-2 to metformin.

\section{Hyperglycaemia impairs PAMPK $^{\text {Thr172 }}$, but not pAMPK ${ }^{\text {Ser485 }}$ activation}

To determine if the reduced efficacy of metformin during hyperglycaemic conditions was related to altered AMPK activation, metformin-stimulated AMPK phosphorylation in $\mathrm{BxPC}-3$ and MIAPaCa-2 cells during normal or high glucose conditions was examined. These results show that metformin stimulated $\mathrm{AMPK}^{\mathrm{Th} 172}$ phosphorylation in cells cultured in normal glucose $(P<0.01$; Figure $3 \mathrm{~A}, \mathrm{~B}$, D, E). In BxPC-3 cells, metformin-induced AMPK ${ }^{\text {Thr172 }}$ phosphorylation corresponded to a decrease in basal $\mathrm{AMPK}^{\mathrm{Ser} 485}$ phosphorylation (Figure $3 \mathrm{~A}-\mathrm{C}$ ). In contrast, exposure to hyperglycaemic conditions inhibited both basal and metformin-stimulated $\mathrm{pAMPK}^{\text {Thr172 }}$ increase, whereas $\mathrm{AMPK}^{\mathrm{S} 485}$ phosphorylation remained stable. In MIAPaCa-2, metformin induced both $\mathrm{AMPK}^{\text {Thr172 }}$ and AMPK $^{\text {Ser485 }}$ phosphorylation in $5 \mathrm{mM}$ glucose $(P<0.01$; Figure 3D-F). However, exposure to $25 \mathrm{mM}$ glucose almost completely inhibited the metformin-induced increase in AMPK ${ }^{\text {Thr172 }}$ phosphorylation, while AMPK ${ }^{\text {Ser485 }}$ phosphorylation was still present, similar to the effects observed in BxPC-3.

\section{Metformin modulates IRS-1 levels and Akt phosphorylation}

Having shown that high levels of glucose altered the responsiveness to metformin and influenced the AMPK activation pattern, we then examined the involvement of the insulin/IGF-I signalling pathways. As shown in
A

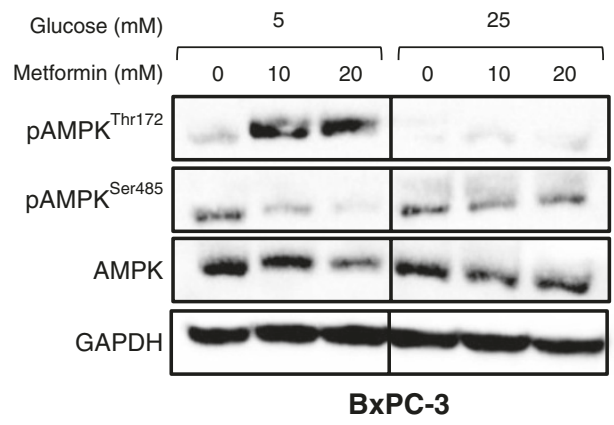

D

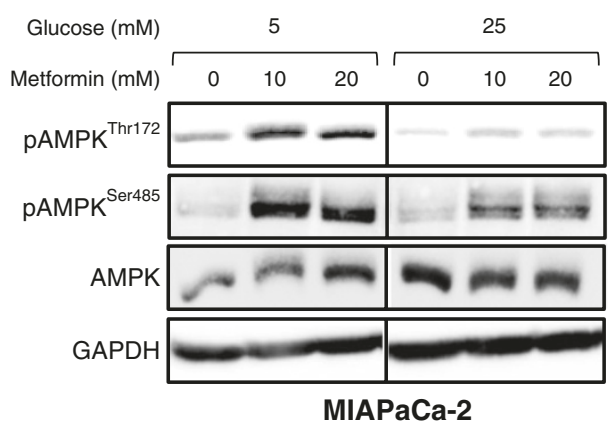

B

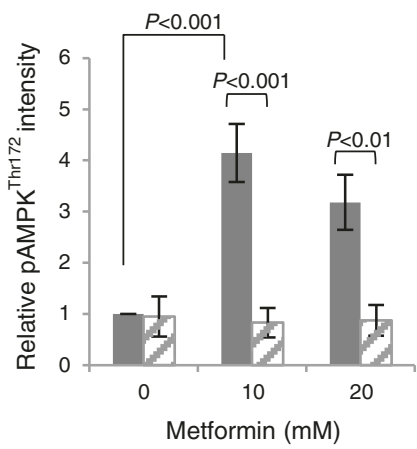

E

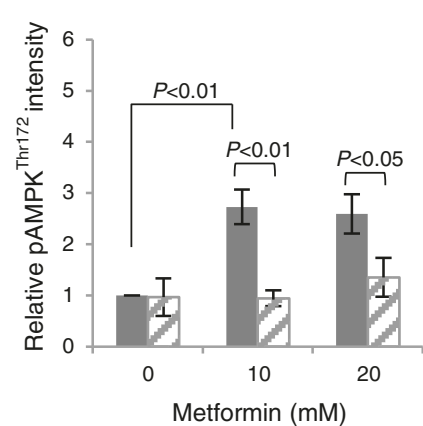

C

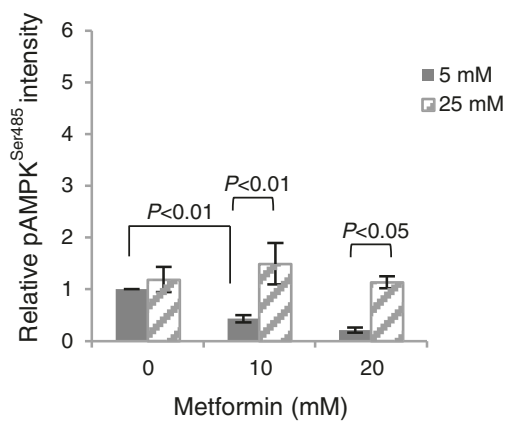

$\mathbf{F}$

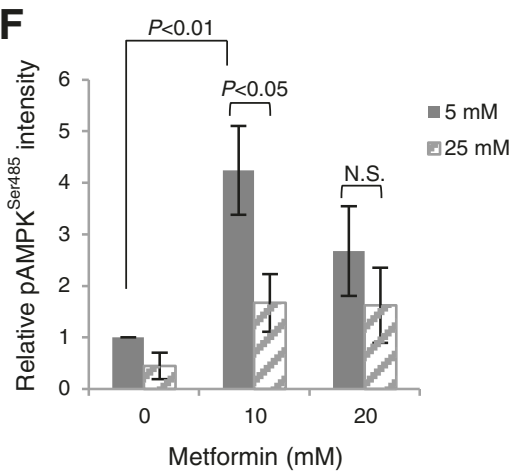

Figure 3 Hyperglycaemia impairs pAMPK ${ }^{\text {Thr172 }}$, but not pAMPK ${ }^{\text {Ser485 }}$ activation. (A-C) BxPC-3 and (D-F) MIAPaCa-2 cells were treated with or without metformin in normal $(5 \mathrm{mM})$ or high $(25 \mathrm{mM})$ glucose-containing media with $1 \%$ FBS for $24 \mathrm{~h}$ and processed for immunoblot analysis using antibodies against PAMPK ${ }^{\text {Thr172 }}$, PAMPK $^{\text {Ser485 }}$ and AMPK. GAPDH is shown as a loading control. Graphs display densitometry measurements of relative levels of AMPK protein phosphorylation at $5 \mathrm{mM}$ (black bars) or $25 \mathrm{mM}$ (striped bars) glucose conditions and represent means \pm SE of three independent experiments. P-values are based on two-way ANOVA with Bonferroni post hoc test. N.S. not significant. One representative blot from three independent experiments is shown. 
Figure 4, metformin exposure resulted in a significant decrease in basal levels of IRS-1 $(P<0.05)$ and Akt ${ }^{\text {Ser473 }}$ $(P<0.01)$ phosphorylation in a dose-dependent manner during normal glucose conditions. In contrast, a high glucose environment counteracted the metformin-mediated IRS-1 and pAkt suppression in BxPC-3 (Figure 4A) and MIAPaCa-2 (Figure 4B).

\section{IGF-I and hyperglycaemia enhance AMPK ${ }^{\text {Ser485 }}$ \\ phosphorylation}

Having found that metformin influenced the IGF-I signalling mediators under normal glucose levels, we next addressed the influence by IGF-I on AMPK activation. No changes in the basal or metformin-induced phosphorylation of $\mathrm{AMPK}^{\mathrm{Thr} 172}$ were observed in response to IGF-I stimulation at normal glucose (Figure 5A-B, D-E). Instead, stimulation of BxPC-3 (Figure 5A, C) and MIAPaCa-2 (Figure 5D, F) cells with $100 \mathrm{ng} / \mathrm{ml}$ IGF-I caused a strong phosphorylation of $\mathrm{AMPK}^{\mathrm{Ser} 485}$. In hyperglycaemia, the IGF-I-induced $\mathrm{AMPK}^{\mathrm{Ser} 485}$ phosphorylation was sustained in both cell lines. This suggested that exposure to IGF-I in combination with higher glucose concentrations stimulated AMPK ${ }^{\text {Ser485 }}$ phosphorylation, which shifted the $\mathrm{AMPK}^{\mathrm{Thr} 172}$ to $\mathrm{AMPK}^{\mathrm{Ser} 485}$ balance.

Metformin inhibits IGF-I-stimulated IGF-IR and Akt activation After studying the influence by IGF-I on AMPK activation, we examined modulation of the IGF-IR pathway by metformin. Interestingly, metformin potently inhibited the activating phosphorylation of the IGF-IR $\beta / \operatorname{IR} \beta(P<0.01)$, and subsequently also the downstream phosphorylation of Akt in both BxPC-3 $(P<0.01)$ and MIAPaCa-2 $(P<0.05)$ cells at normal glucose levels (Figure 6). However, in the hyperglycaemic situation, the IGF-I-mediated IGF-IR $\beta /$ IR $\beta$ and Akt activation appeared to be more robust and could override the inhibitory action of metformin. The sustained IGF-IR $\beta / \operatorname{IR} \beta$ and Akt activation correlated with the observed activation of $\mathrm{AMPK}^{\mathrm{Ser} 485}$, supporting the hypothesis of a link between the two pathways.

\section{Discussion}

Type 2 diabetes or impaired glucose tolerance frequently occurs in pancreatic cancer patients. Compared to other treatments, diabetic patients on metformin have a reduced risk of approximately $40 \%$ of developing several types of

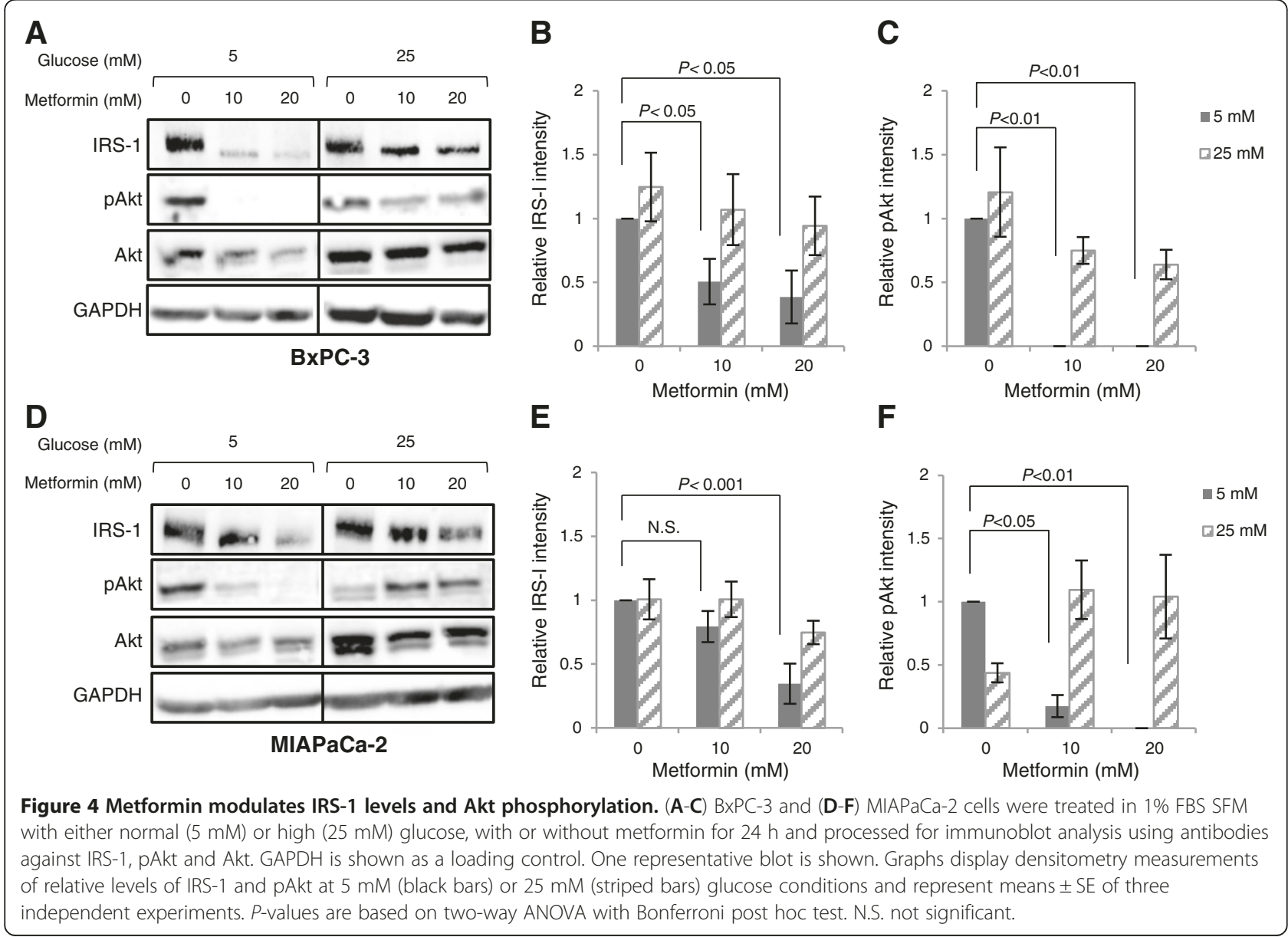




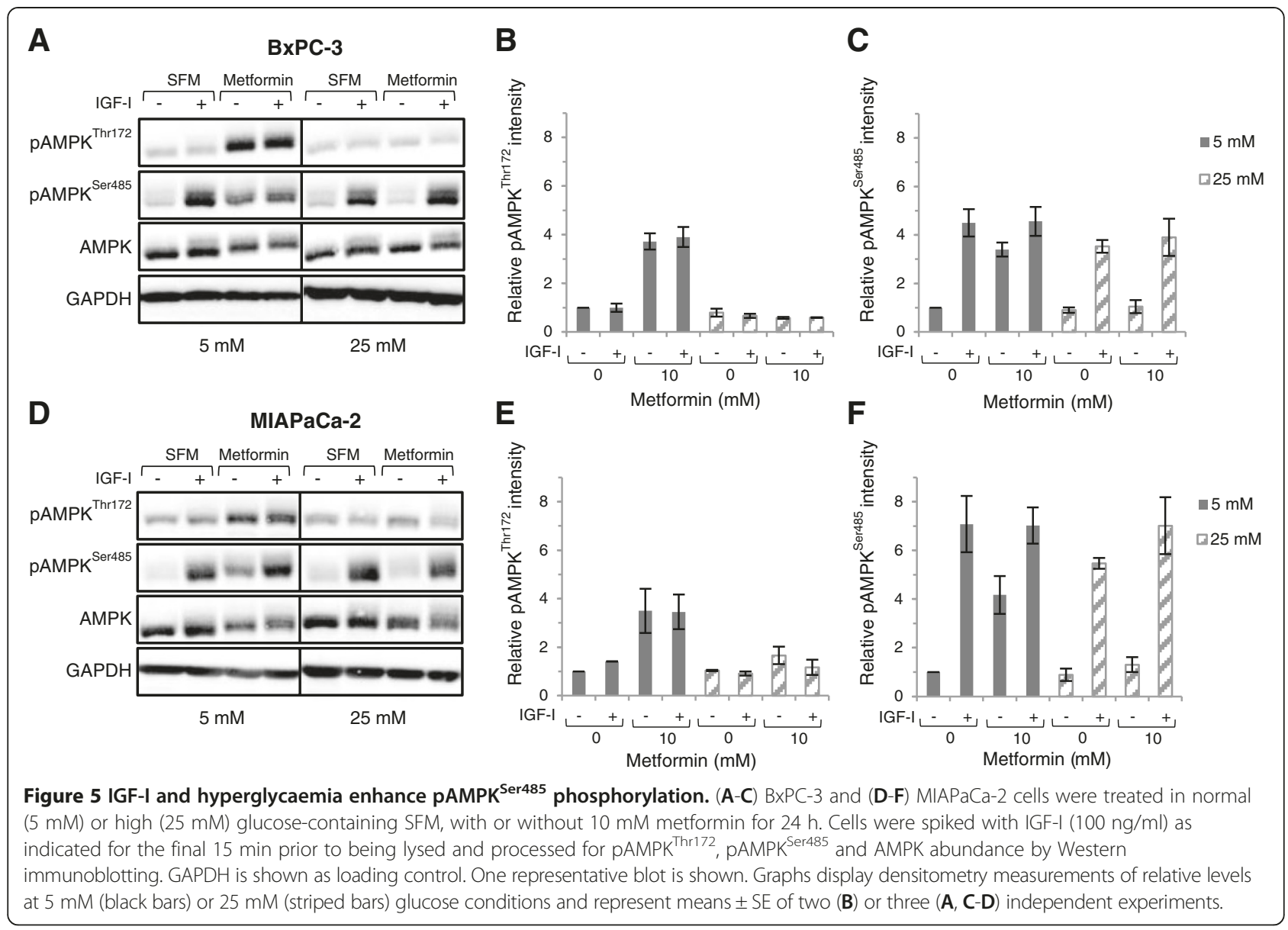

cancer, including pancreatic cancer [19-21]. However, the molecular relationships underlying the metabolic and suggested anti-cancer actions of metformin remain poorly understood. Additionally, the importance of optimal glucose control for the anti-tumour effects of metformin has not been fully established. In this study, we describe direct anti-proliferative actions by metformin using in vitro models of pancreatic cancer. In addition, we demonstrate that elevated glucose levels impair AMPK activation and reduce the efficacy of metformin. Importantly, we show a novel role for metformin on human pancreatic cancer cells that may contribute to its indicated anti-cancer actions among type 2 diabetic patients.

Metformin is believed to act mainly through activation of the energy-conserving LKB1-AMPK pathway. Physiological activation of the AMPK metabolic checkpoint in response to nutrient depletion and energy stress suppresses energy-consuming cellular processes such as protein synthesis and cell division. We found that metformin during normal glucose conditions significantly reduced proliferation and promoted apoptosis through PARP cleavage in pancreatic cancer cells with functional LKB1 (MIAPaCa-2, BxPC-3 and PANC-1), while being incapable of suppressing growth under the same conditions in AsPC-1 pancreatic cancer cells. AsPC-1 cells have previously been reported to carry an epigenetic inactivation of LKB1 [27]. Our findings are consistent with prior observations, showing pro-apoptotic actions on breast cancer cells $[28,29]$ and that a functional LKB1 was required for the in vitro anti-proliferative effect of metformin [25,30].

Previous work indicates that metformin functions by activating AMPK at $\mathrm{Thr}^{172}$ with subsequent downstream inhibition of the growth promoting PI3K/Akt/mTOR pathway $[29,31,32]$. Similarly, we also found the growth inhibitory properties of metformin to be associated with the activation of AMPK ${ }^{\text {Thr172 }}$ in pancreatic cancer cells. Under hyperglycaemic conditions, the efficacy of metformin was reduced with less anti-proliferative and pro-apoptotic activity observed. Other investigators have reported that lung and colon carcinoma cells were more sensitive to metformin-induced growth inhibition at low glucose concentrations, while no significant effect of metformin on cell death was observed in high glucose conditions [30]. Similarly, a recent study demonstrated anti-proliferative effects on pancreatic cancer cells by metformin at the low $0.05-1 \mathrm{mM}$ range at normal $(5 \mathrm{mM})$ glucose conditions 


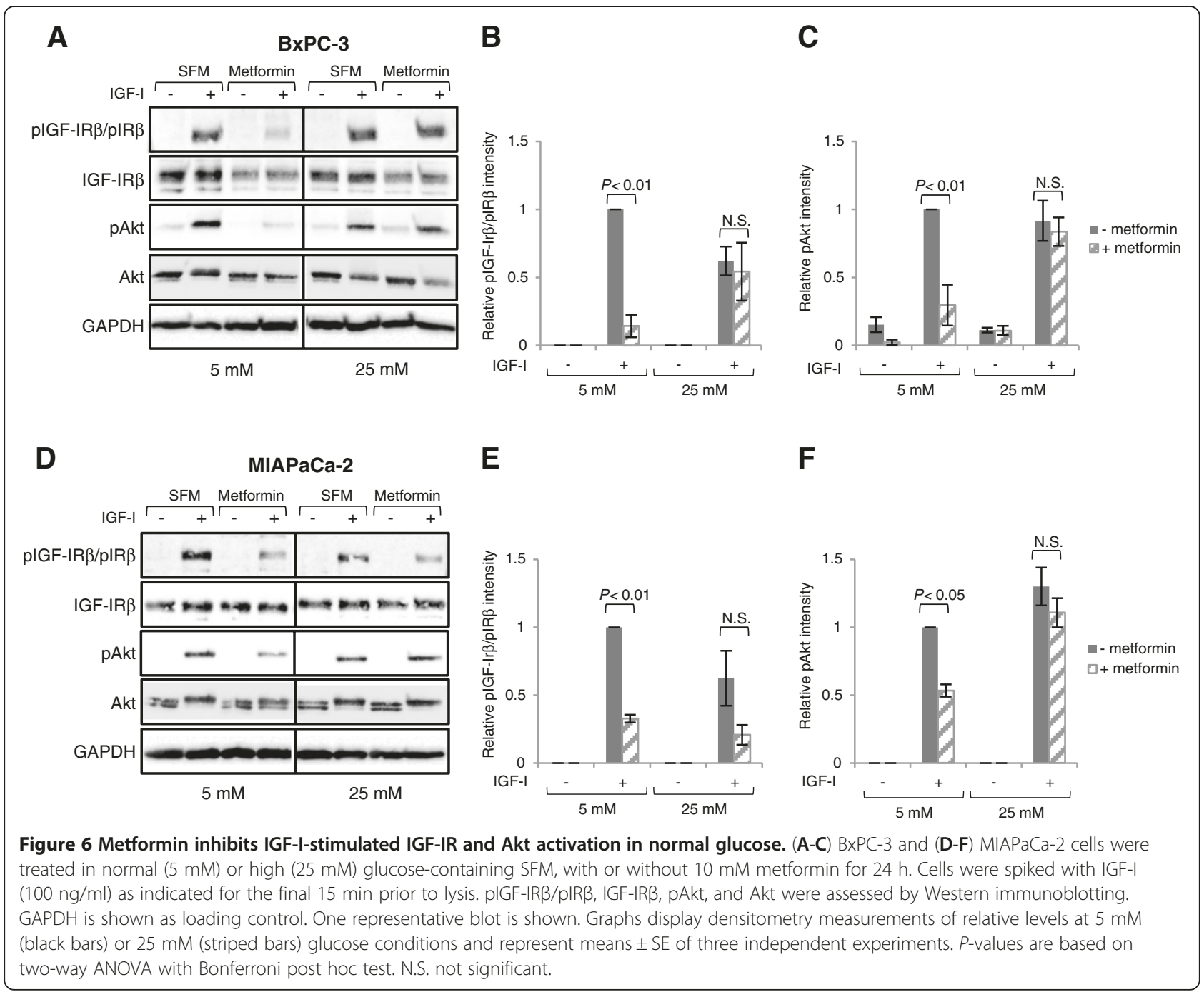

[33]. This study is in concordance with our data demonstrating direct anti-tumour effects of metformin and supports our findings of enhanced sensitivity at physiological normal glucose levels. We have now shown that the lower anti-proliferative effect of metformin on pancreatic cancer cells at higher glucose levels correlates to an impaired AMPK $^{\text {Thr172 }}$ activation and a shifted balance from AMPK $^{\text {Thr172 }}$ towards AMPK ${ }^{\text {Ser485 }}$ activation. The role of $\mathrm{AMPK}^{\mathrm{Ser} 485}$ in the complex AMPK signaling network is at present not completely clear and conflicting reports exist. A recent study indicated that endogenous protein kinase A (PKA)-induced activation of AMPK ${ }^{\mathrm{Ser} 485}$ in pancreatic beta cells did not affect the phosphorylation status of $\mathrm{AMPK}^{\text {Thr172 }}$. However, the activation of $\mathrm{Thr}^{172}$ and $\mathrm{Ser}^{485}$ were inversely correlated in response to glucose [34]. Other studies have proposed that PKB/Aktinduced phosphorylation of $\mathrm{AMPK}^{\mathrm{Ser} 485}$ can counteract AMPK $^{\text {Thr172 }}$ activation, thereby reducing the effects of metformin $[31,32,35]$.
Hyperinsulinemia with resulting increased circulating levels of IGF-I have been suggested to play a role in the connection between type 2 diabetes and cancer [36]. Activation of the IR and IGF-IR result in receptor autophosphorylation and recruitment of insulin receptor substrate (IRS) 1, which in turn activates the PI3K/Akt pathway leading to protein synthesis and cell survival [14]. The responsiveness to IGF-I can be enhanced by exposure to high glucose concentrations [4], which may then further promote cancer progression. In pancreatic cancer cells, IGF-I stimulated a pronounced phosphorylation of Akt and also $\mathrm{AMPK}^{\mathrm{Ser} 485}$. However, at physiologically normal glucose levels, IGF-I stimulated AMPK ${ }^{\mathrm{Ser} 485}$ phosphorylation did not appear to antagonize pharmacological activation of AMPK ${ }^{\text {Thr172 }}$ by metformin. Instead, we established that metformin under these conditions suppressed IGF-IR/IR phosphorylation causing a downstream inhibition of both basal and IGF-I stimulated Akt phosphorylation. It is well established that IGF-IR 
via activation by its ligands transmits mitogenic signals leading to the survival and proliferation of multiple types of cancer. Mechanisms by which metformin inhibits these pathways may thus contribute to the anti-tumour effects previously observed in response to metformin. Studies in other cell types have shown that during normal glucose conditions, AMPK $^{\text {Thr172 }}$ can phosphorylate inhibitory serine residues on IRS-1, which prevents signalling

\section{A}

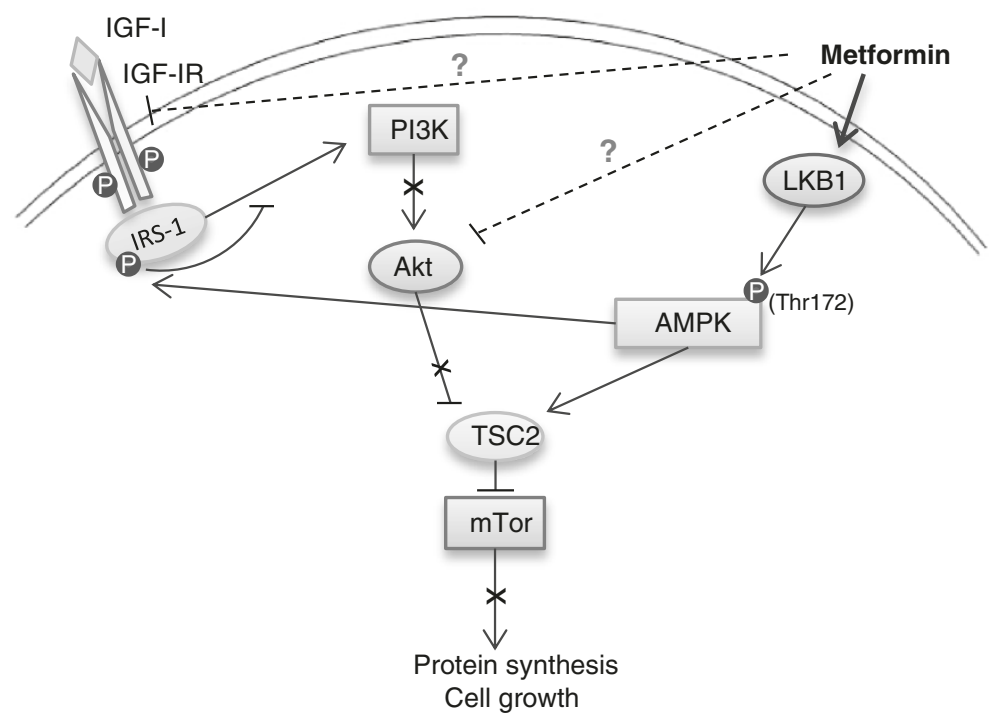

B

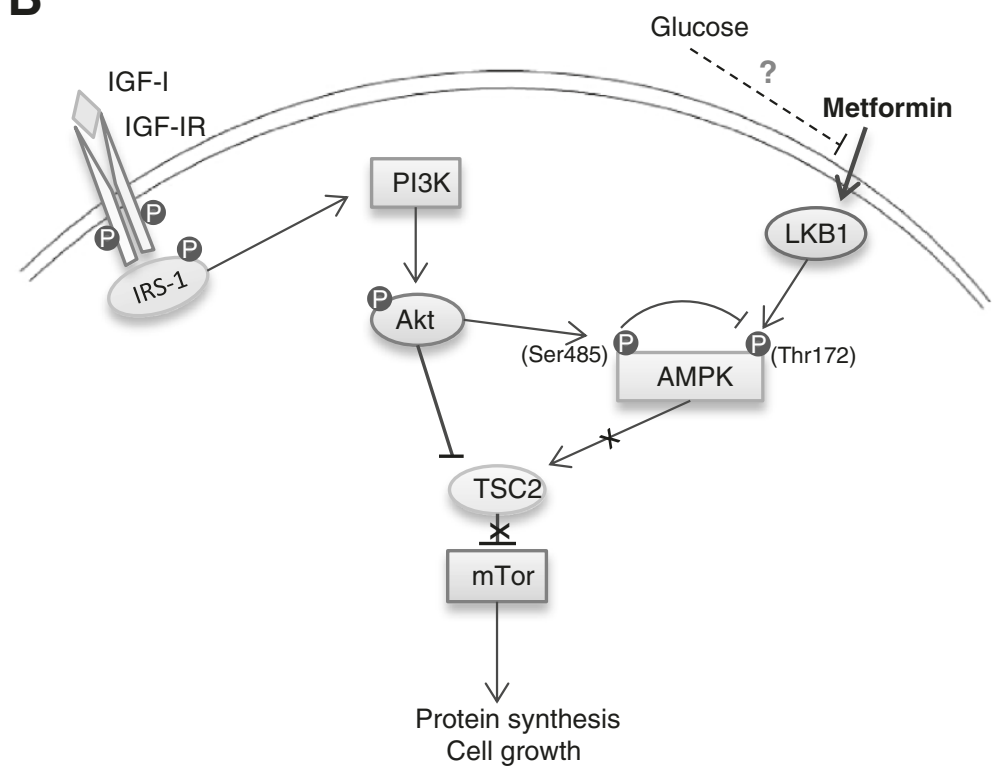

Figure 7 Overview of selected AMPK and IGF-IR signalling pathways relevant to this study in normal (A) and hyperglycaemic (B) conditions. In normal conditions, metformin activates AMPK ${ }^{\text {Thr172 }}$ through the LKB1 signalling pathway. Activated AMPK inhibits cell growth by repressing mTOR activity through activation of TSC2 and phosphorylation of inhibitory serine residues on IRS-1. In addition, as demonstrated in the present study, metformin suppresses IGF-IR activation and reduces IRS-1 levels, which disable further signalling through the PI3K/Akt pathway. During hyperglycaemia, signalling through the IGF-IR pathway appears more robust, leading to phosphorylation of Akt and AMPK ${ }^{\text {Ser485. }}$. This inhibitory Ser485 site can inhibit activation of AMPK ${ }^{\text {Thr172, }}$, possibly contributing to the impaired growth inhibitory effect by metformin at high glucose conditions. 
through the PI3K/Akt pathway [29,37]. However, studies have also shown that Akt at high glucose conditions can inhibit AMPK by phosphorylation of $\mathrm{Ser}^{485}$, which prevents activation of $\mathrm{Thr}^{172}$ and thereby the action of metformin $[29,31,35,37,38]$. In keeping with this, we observed a strong activation of Akt and AMPK ${ }^{\text {Ser485 }}$ following IGF-I stimulation at high glucose, which was sustained after exposure to metformin. At high glucose, IGF-I induced Akt and $\mathrm{AMPK}^{\mathrm{Ser} 485}$ phosphorylation appeared to correlate with a further reduction of the already-impaired AMPK $^{\text {Thr172 }}$ phosphorylation by metformin.

\section{Conclusions}

The findings of the current study using human pancreatic cancer cells add novel information to the indications of direct anti-tumour actions by metformin on transformed epithelial cells. Metformin mediated its effects through activation of $\mathrm{AMPK}^{\mathrm{Thr} 172}$ together with inhibition of the IR/IGF-IR signalling pathway (Figure 7). Hyperglycaemia, with and without IGF-I, reduced the sensitivity to metformin and counteracted the growth inhibitory effect otherwise exerted by the drug. Our data suggests that metformin may have beneficial effects on tumour prevention or protection in non-diabetic patients with normal glucose levels. Importantly, these data indicate that optimizing glucose control in type 2 diabetic patients may improve the beneficial anti-tumour actions provided by metformin and should thus be further investigated. Due to the strong associations between type 2 diabetes and pancreatic cancer, evaluating the potential beneficial effects by metformin, as well as the impact by different glucose levels, should be considered of utmost importance. Increased understanding of the relationship between the two conditions may improve both future treatment strategies as well as potentially providing possibilities of novel early diagnostic approaches.

\begin{abstract}
Abbreviations
AMPK: Adenosine monophosphate activated protein kinase; IGF: Insulin-like growth factor; IGF-IR: Insulin-like growth factor type I receptor; IR: Insulin receptor; IRS-1: Insulin receptor substrate-1; PARP: Poly(ADP-ribose) polymerase.
\end{abstract}

Competing interests

The authors declare that they have no competing interests.

\section{Authors' contributions}

AHR designed the study. EK, KS and AHR made significant contributions to the experimental design, acquisition and interpretation of data, manuscript preparation and editing. RA and AHR provided funding for the study and manuscript editing. All authors read and approved the final manuscript.

\section{Acknowledgements}

We thank Michael Deacon for proofreading the manuscript. This study was supported by grants from the South Swedish Health Care Region, Lund Hospital Fund, the Royal Physiographic Society Lund and the Lars Hierta Memorial Foundation.

Received: 9 October 2012 Accepted: 30 April 2013

Published: 10 May 2013

\section{References}

1. Pisani P: Hyper-insulinaemia and cancer, meta-analyses of epidemiological studies. Arch Physiol Biochem 2008, 114(1):63-70.

2. Huxley R, Ansary-Moghaddam A, Berrington de Gonzalez A, Barzi F, Woodward M: Type-II diabetes and pancreatic cancer: a meta-analysis of 36 studies. Br J Cancer 2005, 92(11):2076-2083.

3. Calle EE, Rodriguez C, Walker-Thurmond K, Thun MJ: Overweight, obesity, and mortality from cancer in a prospectively studied cohort of U.S. Adults. N Engl J Med 2003, 348(17):1625-1638.

4. Becker S, Dossus L, Kaaks R: Obesity related hyperinsulinaemia and hyperglycaemia and cancer development. Arch Physiol Biochem 2009, 115(2):86-96.

5. Everhart J, Wright D: Diabetes mellitus as a risk factor for pancreatic cancer. A meta-analysis. JAMA 1995, 273(20):1605-1609.

6. Bao B, Wang Z, Li Y, Kong D, Ali S, Banerjee S, Ahmad A, Sarkar FH: The complexities of obesity and diabetes with the development and progression of pancreatic cancer. Biochim Biophys Acta 2011, 1815(2):135-146.

7. Michaud DS, Wolpin B, Giovannucci E, Liu S, Cochrane B, Manson JE, Pollak MN, Ma J, Fuchs CS: Prediagnostic plasma C-peptide and pancreatic cancer risk in men and women. Cancer Epidemiol Biomarkers Prev 2007, 16(10):2101-2109.

8. Larsson SC, Orsini N, Wolk A: Body mass index and pancreatic cancer risk: a meta-analysis of prospective studies. Int J Cancer 2007, 120(9):1993-1998.

9. Pannala R, Basu A, Petersen GM, Chari ST: New-onset diabetes: a potential clue to the early diagnosis of pancreatic cancer. Lancet Oncol 2009, 10(1):88-95.

10. Bartosch-Harlid A, Andersson R: Diabetes mellitus in pancreatic cancer and the need for diagnosis of asymptomatic disease. Pancreatology 2010, 10(4):423-428

11. Stattin $P$, Bjor $O$, Ferrari $P$, Lukanova $A$, Lenner $P$, Lindahl B, Hallmans $G$, Kaaks R: Prospective study of hyperglycemia and cancer risk. Diabetes Care 2007, 30(3):561-567.

12. Grote VA, Rohrmann S, Nieters A, Dossus L, Tjonneland A, Halkjaer J, Overvad K, Fagherazzi G, Boutron-Ruault MC, Morois S, et al: Diabetes mellitus, glycated haemoglobin and C-peptide levels in relation to pancreatic cancer risk: a study within the european prospective investigation into cancer and nutrition (EPIC) cohort. Diabetologia 2011, 54(12):3037-3046.

13. Seshasai SR, Kaptoge S, Thompson A, Di Angelantonio E, Gao P, Sarwar N, Whincup PH, Mukamal KJ, Gillum RF, Holme I, et al: Diabetes mellitus, fasting glucose, and risk of cause-specific death. N Engl J Med 2011, 364(9):829-841.

14. Pollak M: Insulin and insulin-like growth factor signalling in neoplasia. Nat Rev Cancer 2008, 8(12):915-928.

15. Shaw RJ, Lamia KA, Vasquez D, Koo SH, Bardeesy N, Depinho RA, Montminy M, Cantley LC: The kinase LKB1 mediates glucose homeostasis in liver and therapeutic effects of metformin. Science 2005, 310(5754):1642-1646.

16. United Kingdom Prospective Diabetes Study (UKPDS): 13: Relative efficacy of randomly allocated diet, sulphonylurea, insulin, or metformin in patients with newly diagnosed non-insulin dependent diabetes followed for three years. BMJ 1995, 310(6972):83-88.

17. Effect of intensive blood-glucose control with metformin on complications in overweight patients with type 2 diabetes (UKPDS 34). UK Prospective Diabetes Study (UKPDS) Group. Lancet 1998, 352(9131):854-865.

18. Li D, Abbruzzese JL: New strategies in pancreatic cancer: emerging epidemiologic and therapeutic concepts. Clin Cancer Res 2010, 16(17):4313-4318.

19. Li D, Yeung SC, Hassan MM, Konopleva M, Abbruzzese JL: Antidiabetic therapies affect risk of pancreatic cancer. Gastroenterology 2009, 137(2):482-488.

20. Decensi A, Puntoni M, Goodwin P, Cazzaniga M, Gennari A, Bonanni B, Gandini S: Metformin and cancer risk in diabetic patients: a systematic review and meta-analysis. Cancer Prev Res (Phila) 2010, 3(11):1451-1461.

21. Currie CJ, Poole CD, Gale EA: The influence of glucose-lowering therapies on cancer risk in type 2 diabetes. Diabetologia 2009, 52(9):1766-1777.

22. Shackelford DB, Shaw RJ: The LKB1-AMPK pathway: metabolism and growth control in tumour suppression. Nat Rev Cancer 2009, 9(8):563-575.

23. Schneider MB, Matsuzaki H, Haorah J, Ulrich A, Standop J, Ding XZ, Adrian TE, Pour PM: Prevention of pancreatic cancer induction in hamsters by metformin. Gastroenterology 2001, 120(5):1263-1270.

24. Ben Sahra I, Laurent K, Loubat A, Giorgetti-Peraldi S, Colosetti P, Auberger P, Tanti JF, Le Marchand-Brustel Y, Bost F: The antidiabetic drug metformin exerts an antitumoral effect in vitro and in vivo through a decrease of cyclin D1 level. Oncogene 2008, 27(25):3576-3586. 
25. Zakikhani M, Dowling R, Fantus IG, Sonenberg N, Pollak M: Metformin is an AMP kinase-dependent growth inhibitor for breast cancer cells. Cancer Res 2006, 66(21):10269-10273.

26. Rosendahl AH, Gundewar C, Said K, Karnevi E, Andersson R: Celecoxib synergizes human pancreatic ductal adenocarcinoma cells to sorafenib-induced growth inhibition. Pancreatology 2012, 12(3):219-226.

27. Qanungo S, Haldar S, Basu A: Restoration of silenced peutz-jeghers syndrome gene, LKB1, induces apoptosis in pancreatic carcinoma cells. Neoplasia 2003, 5(4):367-374.

28. Zhuang Y, Miskimins WK: Metformin induces both caspase-dependent and poly(ADP-ribose) polymerase-dependent cell death in breast cancer cells. Mol Cancer Res 2011, 9(5):603-615.

29. Zakikhani M, Blouin MJ, Piura E, Pollak MN: Metformin and rapamycin have distinct effects on the AKT pathway and proliferation in breast cancer cells. Breast Cancer Res Treat 2010, 123(1):271-279.

30. Algire C, Amrein L, Bazile M, David S, Zakikhani M, Pollak M: Diet and tumor LKB1 expression interact to determine sensitivity to anti-neoplastic effects of metformin in vivo. Oncogene 2011, 30(10):1174-1182.

31. Ning J, Xi G, Clemmons DR: Suppression of AMPK activation via S485 phosphorylation by IGF-I during hyperglycemia is mediated by AKT activation in vascular smooth muscle cells. Endocrinology 2011, 152(8):3143-3154.

32. Gonzalez-Angulo AM, Meric-Bernstam F: Metformin: a therapeutic opportunity in breast cancer. Clin Cancer Res 2010, 16(6):1695-1700.

33. Sinnett-Smith J, Kisfalvi K, Kui R, Rozengurt E: Metformin inhibition of mTORC1 activation, DNA synthesis and proliferation in pancreatic cancer cells: dependence on glucose concentration and role of AMPK. Biochem Biophys Res Commun 2013, 430(1):352-357.

34. Garcia-Haro L, Garcia-Gimeno MA, Neumann D, Beullens M, Bollen M, Sanz $P$ : Glucose-dependent regulation of AMP-activated protein kinase in MIN6 beta cells is not affected by the protein kinase a pathway. FEBS Lett 2012, 586(23):4241-4247.

35. Hahn-Windgassen A, Nogueira V, Chen CC, Skeen JE, Sonenberg N, Hay N: Akt activates the mammalian target of rapamycin by regulating cellular ATP level and AMPK activity. J Biol Chem 2005, 280(37):32081-32089.

36. Magruder JT, Elahi D, Andersen DK: Diabetes and pancreatic cancer: chicken or egg? Pancreas 2011, 40(3):339-351.

37. Ning J, Clemmons DR: AMP-activated protein kinase inhibits IGF-I signaling and protein synthesis in vascular smooth muscle cells via stimulation of insulin receptor substrate $1 \mathrm{S794}$ and tuberous sclerosis 2 S1345 phosphorylation. Mol Endocrinol 2010, 24(6):1218-1229.

38. Memmott RM, Mercado JR, Maier CR, Kawabata S, Fox SD, Dennis PA: Metformin prevents tobacco carcinogen-induced lung tumorigenesis. Cancer Prev Res (Phila) 2010, 3(9):1066-1076.

doi:10.1186/1471-2407-13-235

Cite this article as: Karnevi et al:: Metformin-mediated growth inhibition involves suppression of the IGF-I receptor signalling pathway in human pancreatic cancer cells. BMC Cancer 2013 13:235.

\section{Submit your next manuscript to BioMed Central and take full advantage of:}

- Convenient online submission

- Thorough peer review

- No space constraints or color figure charges

- Immediate publication on acceptance

- Inclusion in PubMed, CAS, Scopus and Google Scholar

- Research which is freely available for redistribution 